\title{
Direct and Indirect Nucleation of Magnetite Nanoparticles from Solution Revealed by Time-Resolved Raman Spectroscopy
}

\author{
German Montes-Hernandez ${ }^{\mathrm{a}}$, Nathaniel Findling ${ }^{\mathrm{a}}$, François Renard ${ }^{\mathrm{a}, \mathrm{b}}$
}

${ }^{a}$ Univ. Grenoble Alpes, Univ. Savoie Mont Blanc, CNRS, IRD, IFSTTAR, ISTerre, 38000 Grenoble, France

${ }^{\mathrm{b}}$ The Njord Centre, Department of Geosciences, University of Oslo, box 1048 Blindern, 0316 Oslo, Norway

*Corresponding author: Dr. German Montes-Hernandez

E-mail address: german.montes-hernandez@univ-grenoble-alpes.fr 


\begin{abstract}
Magnetite is a widespread inorganic or bio-mineral with very specific and extraordinary chemical properties in terms of acid-base and oxidation-reduction behavior, thermal stability and oxygen mobility. Despite the existence of many synthesis methods, the formation mechanisms of this mineral are actively investigated and frequently debated. The co-precipitation reaction $\left(2 \mathrm{Fe}^{3+}+\right.$ $\left.\mathrm{Fe}^{2+}+8 \mathrm{OH}^{-} \rightarrow \mathrm{Fe}_{3} \mathrm{O}_{4}+4 \mathrm{H}_{2} \mathrm{O}\right)$ is the most widespread method to synthesize magnetite under laboratory conditions and at industrial scale. However, the early stages of magnetite formation nucleation events and precursors/transient phases formation - are still questioned and their kinetics is poorly characterized. Here, we perform two series of experiments that differ by how the solutions are mixed: i) injection of an iron-rich solution into an alkaline aqueous solution; and ii) injection of an alkaline solution into an iron-rich solution. We show that dynamic in situ Raman spectroscopy provides invaluable information on the direct and indirect nucleation of magnetite nanoparticles $(<15 \mathrm{~nm})$ from aqueous solution. When a mixed-valent iron solution $\left(0.5 \mathrm{M} \mathrm{Fe}^{2+}+0.5 \mathrm{M} \mathrm{Fe}^{3+}\right)$ is injected ( 2.3 or $12 \mathrm{ml} / \mathrm{minute})$ into an alkaline solution $(4 \mathrm{M}$ of $\mathrm{NaOH})$; dark colloidal particles form instantaneously and the magnetite signal is rapidly detected in Raman spectra after 3 or 7 minutes, depending of the injection rate. This result demonstrates that the mixed-valent iron is instantaneously dehydrated leading to the formation of magnetite-like colloidal (or primary) particles peaking in the range $674-678 \mathrm{~cm}^{-1}$ in the Raman spectra, with peak position stabilizing rapidly at $673 \mathrm{~cm}^{-1}$. Conversely, when alkaline solution is added into the mixed-valent iron solution, Raman spectroscopy reveals a complex reaction mechanism and kinetics. Firstly, iron dehydration $\left(315 \mathrm{~cm}^{-1}\right)$ and formation of green rust $\left(500-503 \mathrm{~cm}^{-1}\right)$ as transient phase related to olation process are detected and interpreted by the formation of hydroxo bridges accompanied with
\end{abstract}


expelling of molecular water. Secondly, green rust and available ferric iron (ions or colloids) react to nucleate magnetite nanoparticles via an oxolation process related to the formation of oxo bridges accompanied with the expelling of hydroxylated water. We also quantified the nucleation time of magnetite and the hydrophilic-to-hydrophobic change in the suspension by the temporal behavior of bending mode of molecular water. Our results show that, under our experimental conditions, amorphous transient phases during direct or indirect magnetite formation from ionic solutions do not exist or that such phases do not show a specific Raman signature. 
Keywords: Magnetite nanoparticles, Co-precipitation, Nucleation and growth processes; Timeresolved Raman spectroscopy; Iron oxide 


\section{Introduction}

Inorganic iron oxide and (oxy)hydroxide nanoparticles are extensively used in a range of applications in biomedicine, magnetic storage media, water treatment and catalysis (1-4). Among these minerals, magnetite is a ubiquitous mixed-valent iron oxide mineral $\left(\mathrm{Fe}_{3} \mathrm{O}_{4}\right.$ or $\left.\mathrm{FeO} \cdot \mathrm{Fe}_{2} \mathrm{O}_{3}\right)$ found in many Earth and planetary environments (5-6). Magnetite has a biomineral origin when formed inside organisms such as magnetotactic bacteria, mollusks, termites, bees, birds, and dolphins (7-8). Recently, magnetite engineered nanoparticles (MNPs) have found many applications (1-4). In the field of nanomedicine, they are used because of their specific magnetic properties and size ranges (1). However, and despite many investigations on the synthesis and sophisticated analytical characterization of particles, the details on the formation mechanism and kinetics (including nucleation and growth processes) remain to be understood (9-12) because more than one crystallization pathway may exist (13). For example, the most widely used coprecipitation reaction $\left(2 \mathrm{Fe}^{3+}+\mathrm{Fe}^{2+}+8 \mathrm{OH}^{-} \rightarrow \mathrm{Fe}_{3} \mathrm{O}_{4}+4 \mathrm{H}_{2} \mathrm{O}\right)$ to produce magnetite under laboratory and at industrial scale, is performed by using aqueous solutions containing ferric $\left(\mathrm{Fe}^{3+}\right)$ and ferrous $\left(\mathrm{Fe}^{2+}\right)$ ions, to which a base is added at moderate temperatures $\left(<100{ }^{\circ} \mathrm{C}\right)$. The controlled addition of iron solution into alkaline solution or a fast mixing of both solutions have also been investigated (14-25). Herein, several studies have claimed that magnetite crystallization is preceded by the formation of various transient crystalline or poorly-crystallized phases (akageneite, goethite, lepidocrocite, ferrihydrite, ferric hydroxide and ferrous hydroxide) that may become sequentially transformed into magnetite, depending on several control parameters such as the addition rate of solution, the ratio $\mathrm{OH} /\left(\mathrm{Fe}^{+3}+\mathrm{Fe}^{+2}\right)$, the initial $\mathrm{pH}$, the molar fraction of $\mathrm{Fe}^{+3}$ $\left(\mathrm{Fe}^{+3} /\left(\mathrm{Fe}^{+3}+\mathrm{Fe}^{+2}\right)\right)$ and the hydrodynamics conditions $(11,26-30)$. Several studies have proposed 
crystallization pathways that involve the formation of pre-nucleation and amorphous iron oxide (AIO) clusters $(<2 \mathrm{~nm})$ for ferric oxides or poorly crystallized transient phase (green rust) for magnetite, during olation and oxolation processes; two fundamental reaction mechanisms than are analogous to a polymerization process $(9,12)$. The olation process corresponds to the formation of hydroxo bridges (-Fe-OH-Fe-) accompanied by expelling of molecular water. The oxolation process is the formation of oxo bridges (-Fe-O-Fe-) accompanied by expelling of molecular water (12). The primary colloidal particles then aggregate, which allows the heterogeneous nucleation of anhydrous iron oxides, including MNPs $(13,23,26,29,31-33)$. This advanced model for magnetite nucleation has been proposed based on data acquired from time-resolved and/or conventional measurements using sophisticated analytical/reactor tools such as liquid-cell transmission electron microscopy (TEM), cryo-TEM, micro-fluidic reactors, titration reactors, dynamic light scattering, analytical ultracentrifugation, synchrotron-based X-ray diffraction, small- and wide-angles X-ray scattering (SAXS/WAXS), atomic force microcopy, and field-emission scanning electron microscopy (FESEM). In these experimental studies, direct nucleation of MNPs from ionic solutions has been rarely invoked and measured $(13,26)$. Two main approaches have been proposed to explain the formation of magnetite. On the one hand, a non-classical crystallization pathway has been proposed in the past years; on the other hand, other studies have proposed that MNPs formation can be described within the framework of classical nucleation theory (CNT) and that an amorphous magnetite-like phase, probably does not exist $(9,13,23,26)$. The first approach has been successfully developed to explain the crystallization of calcium-magnesium carbonates and calcium phosphates minerals (bio-) where the formation of amorphous phases has been observed and the amorphous phases were identified, for example, using real-time in situ Raman spectroscopy (34-36).

6 
Here, dynamic in situ Raman spectroscopy demonstrates for the first time that direct nucleation of MNPs exists when high $\mathrm{pH}(\sim 14)$ is constrained in the system, i.e. when mixed-valent iron solutions are added to a highly concentrated hydroxide solution (4M) at moderate or fast addition rate, 2.3 or $12 \mathrm{ml} /$ minute, respectively. Herein, dark colloidal particles form instantaneously and magnetite nucleation from colloidal matter is detected after only 3 minutes for a fast addition rate and 7 minutes for a moderate addition rate. Amorphous and/or crystalline transient phases are not detected and nucleation is the dominant process as revealed by insignificant variation with time of the full width of half maximum (FWHM) of the strongest Raman peak of magnetite. In contrast, when the concentrated hydroxide solution $(4 \mathrm{M})$ is gradually added $(2.3$ or $12 \mathrm{ml} / \mathrm{minute})$ into the mixed-valent iron solutions (initial $\mathrm{pH} 1,1 \mathrm{M}$ ), indirect nucleation of MNPs is systematically measured by in situ Raman spectroscopy. In this case, red colloidal particles form instantaneously; then, a green rust (mixed-valent iron hydroxylated phase) is firstly nucleated and acts as transient phase that transforms into magnetite. Here, the olation (nucleation of green rust) and oxolation (nucleation of magnetite) processes can be directly monitored. Moreover, the persistence time of green rust and magnetite nucleation time are strongly related to the rate at which the hydroxide solution is added. These results suggest that amorphous transient phases during magnetite formation from ionic solutions do not exist or, if such phases exist, they do not have a detectable Raman signature. Here, primary particles are dark-colored magnetite-like colloids when a direct magnetite nucleation is detected after 3 minutes, and red-colored iron hydroxylated colloids when indirect magnetite nucleation occurred with green rust acting as transient phase. 


\section{Materials and Methods}

\subsection{Direct nucleation of magnetite}

$200 \mathrm{ml}$ of $\mathrm{NaOH}$ solution $(4 \mathrm{M}, \mathrm{pH}=14)$ were initially placed into a Hastelloy $\mathrm{C} 22$ reactor (Parr, total internal volume of $600 \mathrm{~mL}$ ) coupled with a Raman probe immerged into solution/suspension in order to monitor in real time the precipitating particles and aqueous species at room temperature $\left(\sim 26^{\circ} \mathrm{C}\right)$. Agitation system at 400rpm and acquisition of Raman spectra were turned on prior to the addition of $200 \mathrm{~mL}$ of a mixed-valent iron solution $\left(1 \mathrm{M}\right.$ of $\left.\left(\mathrm{Fe}^{2+}+\mathrm{Fe}^{3+}\right), \mathrm{pH} 1\right)$. The addition of this solution was performed at two different rates, either $12 \mathrm{ml} / \mathrm{minute}$ or $2.3 \mathrm{ml} / \mathrm{min}$. Under these conditions, the $\mathrm{pH}$ in the solution/suspension remains close to 14 during the experiments. The experiments were monitored by Raman spectroscopy for one to three days, with an acquisition frequency of one Raman spectrum every minute during the first three hours and every five minutes in the remaining time. Raman spectra were collected with a Raman RXN1, Kaiser Optical Systems with an exposure time of three seconds and averaged over three scans. This experimental setup was used in previous studies to monitor the nucleation of carbonates and phosphates (34-37).

In the present experiments, the strongest signal of magnetite at $673 \mathrm{~cm}^{-1}$ and bending vibration mode of molecular water in the suspension at $1645 \mathrm{~cm}^{-1}$ are the main Raman peaks. The intensity of these peaks varies with time (Figure S1).

Temperature effect $\left(90^{\circ} \mathrm{C}\right)$, presence of citric acid and $\mathrm{Fe}^{2+}$ molar fraction, were also assessed and their effects are shown in Figure S2 and S3, respectively. The Table 1 contains all experiments performed in the present study; each experiment was repeated at least twice to verify reproducibility of the results. 


\subsection{Indirect nucleation of magnetite}

The same experimental protocol as above was followed, but, in this case $200 \mathrm{ml}$ of mixed-valent iron solution $\left(1 \mathrm{M}\right.$ of $\left.\left(\mathrm{Fe}^{2+}+\mathrm{Fe}^{3+}\right), \mathrm{pH} 1\right)$ were initially placed into the reaction cell and then the alkaline solution $(200 \mathrm{ml}$ of $\mathrm{NaOH} 4 \mathrm{M})$ was added at two different rates, 12 and $2.3 \mathrm{ml} /$ minute (Table 1) In this case, the $\mathrm{pH}$ increases from 1 to 14 during the experiments, leading to a more complex reaction mechanism and kinetics as monitored in real-time by Raman spectroscopy (Figure S4). Here, four main Raman peaks vary with time. They are located at $315 \mathrm{~cm}^{-1}$, assigned to the main ferric iron specie (trans- $\left.\left[\mathrm{FeCl}_{2}\left(\mathrm{H}_{2} \mathrm{O}\right) 4\right]^{+}\right)$present initially in the iron solution, $500 \mathrm{~cm}^{-}$

1, assigned to green rust (a transient phase), $671 \mathrm{~cm}^{-1}$, assigned to magnetite (stable phase) and $1645 \mathrm{~cm}^{-1}$, assigned to the bending vibration mode of molecular water (indicator of the hydrophilic/hydrophobic property in the suspension).

Selected Raman peaks corresponding to identified mineral phases, initial hydration of iron and bending vibration mode of molecular water for direct and indirect magnetite formation (see Table S1) were fitted by using a simple Gaussian function in order to estimate both the full wide half maximum (FWHM) and integrated peak area as a function of time. These two fundamental parameters quantify the nucleation time of transient or stables phase, lifetime or persistence time of transient phases and growth process during formation of magnetite.

\subsection{Ex situ characterization of precipitates}

At the end of each experiment, the solid product was recovered by centrifugation and washed twice with ultrapure water, and once with ethanol. Then, it was dried under air atmosphere at $60^{\circ} \mathrm{C}$ for 9 
$48 \mathrm{~h}$. The dry solid products were stored in plastic flasks for subsequent characterization of selected samples by Field Emission Gun Scanning Electron Microscopy (FESEM) and powder X-ray diffraction (XRD).

Powder XRD spectra were acquired using a Siemens D5000 diffractometer in Bragg-Brentano geometry, equipped with a theta-theta goniometer with a rotating sample holder. Diffraction patterns were collected using $\mathrm{Cu} \mathrm{k} \alpha_{1}\left(\lambda_{\mathrm{k} \alpha 1}=1.5406 \AA \hat{)}\right)$ and $\mathrm{Cu} \mathrm{k} \alpha_{2}\left(\lambda_{\mathrm{k} \alpha 2}=1.5444 \AA \hat{)}\right)$ radiations in the range $2 \theta=10-70^{\circ}$, with a step size of $0.04^{\circ}$ and a counting time of six seconds per step. Coherent average size of magnetite was systematically refined by the quantitative Rietveld method on XRD patterns using the BGMN software and its associated database (38). For high-resolution imaging, the solid products were dispersed by ultrasonic treatment in absolute ethanol for five minutes. Two droplets of the suspension were then deposited directly on an aluminum support and observed without metal coating because magnetite nanoparticles have good conductivity. The powder was imaged using a Zeiss Ultra 55 FESEM with a maximum spatial resolution of approximately $1 \mathrm{~nm}$ at $15 \mathrm{kV}$.

\section{Results and discussion}

\subsection{Direct nucleation of magnetite: reaction mechanism and kinetics}

The direct nucleation of magnetite in aqueous media has been rarely invoked in the literature and, to our knowledge, has not been measured experimentally. Many experimental studies were designed to either simulate biomineralization systems or synthesize directly magnetite nanoparticle; these latter studies excluding kinetics and reaction mechanism (1-2). However, the 
direct nucleation of magnetite is thermodynamically possible and, like for other crystals, more than one crystallization pathway may exist, as suggested by De Yoreo (13). Here, we measured the direct nucleation of magnetite experimentally by using a high alkaline-hydroxide solution ( $\mathrm{pH} \sim 14$, $4 \mathrm{M})$ where a mixed-valent iron solution $(\mathrm{pH} \sim 1,1 \mathrm{M})$ was added at controlled flow rate (2.3 and 12 $\mathrm{ml} /$ minute, see also Figure $\mathrm{S} 1$ ). The $\mathrm{pH}$ in the interacting solution is close to 14 and is expected to remain constant during and after the mixture of solutions. Herein, dark colloidal particles instantaneously form and their Raman signature is characterized by a broad band with a maximum position between 674 and $678 \mathrm{~cm}^{-1}$ that is detected after 3 minutes for a flow rate of $12 \mathrm{ml} / \mathrm{min}$ and 7 minutes for a flow rate of $2.3 \mathrm{ml} / \mathrm{min}$ (Figure 1). Here, the Raman signal of magnetite stabilizes rapidly at $673 \mathrm{~cm}^{-1}$. This means that the direct nucleation of magnetite particles detected by Raman spectroscopy is roughly proportional to the flow rate at which the solution is added in our experimental conditions. In terms of reaction mechanism, our results suggest that the added mixedvalent iron is instantaneously dehydrated leading to magnetite-like colloidal (or primary) particles, i.e. that olation and oxolation processes, as described by Jolivet et al. (12) occur simultaneously and almost instantaneously at high $\mathrm{pH}(\sim 14)$. In this way, the direct nucleation reaction of magnetite-like particles can be written as follows:

$2\left[\mathrm{FeCl}_{2}\left(\mathrm{H}_{2} \mathrm{O}\right)_{4}\right)^{+}+[\mathrm{FeCl}]^{+}+5 \mathrm{Na}^{+}+8 \mathrm{OH}^{-} \Rightarrow \mathrm{FeO} . \mathrm{Fe}_{2} \mathrm{O}_{3}+5 \mathrm{NaCl}+12 \mathrm{H}_{2} \mathrm{O}$

The ferric $\left[\mathrm{FeCl}_{2}\left(\mathrm{H}_{2} \mathrm{O}\right)_{4}\right]^{+}$species, with a Raman peak at $315 \mathrm{~cm}^{-1}$, co-exist with the $\left[\mathrm{FeCl}\left(\mathrm{H}_{2} \mathrm{O}\right)_{5}\right]^{2+}$ species at $485 \mathrm{~cm}^{-1}$ (broad band and with smaller intensity) and both species are identified in the initial mixed-valent iron solution ( Figure S5). Conversely, ferrous species are not clearly identified by Raman spectroscopy. However, free-water (or more ionic) ferrous ions were assumed at low $\mathrm{pH}(\sim 1)$ (39); for this reason $[\mathrm{FeCl}]^{+}$is considered in reaction 1. In this perspective, the kinetics of reaction 1 is characterized by a hyperbolic behavior that contains an initial fast stage 11 
directly related to addition-time duration of solution, and a slower stage later. This slow stage is probably related to self-assembly aggregation of residual primary or colloidal particles, as revealed when plotting the integrated intensity peak area of magnetite as a function of time (Figure 2). Moreover, the bending mode of molecular water (peak at $1645 \mathrm{~cm}^{-1}$ ) provides clear evidence of a change from hydrophilic to hydrophobic properties during magnetite formation (Figure 2). In fact, magnetite particles formed at the end of the first kinetic step have hydrophobic properties in the dispersed suspension as indicated by a very slight Raman signature of the bending mode of molecular water. This kinetic behavior of the bending mode of molecular water is observed in Figure 2 and Figure S1. The bending mode of water was recently proposed as a parameter that probes hydrogen bond structure in aqueous systems (40).

Concerning the crystal growth process, the full width half maximum (FWHM) of the magnetite peak is a direct indicator of the average crystal size $\mathrm{z}$ because $\mathrm{z} \alpha 1 / \mathrm{FWHM}_{\mathrm{MNPs}}$ (e.g. 41). This means that the crystal growth process leads to a progressive decrease of FWHMMNPs after nucleation. Conversely, an increase of the FWHM parameter of a given mineral phase can be related to a dissolution process, as proposed for carbonates and phosphates (36-37). In this way, the plot FWHM MNPs versus time reveals a very slight crystal growth process after the addition of a mixed-valence iron solution because a slight decrease of FWHM is measured (Figure 3). This result confirms that the slow kinetic step above, described in Figure 2 (slow increase of the integrated peak area of magnetite with time), is mainly related to the interaction of residual primary particles and not to a specific crystal growth process. We then conclude that magnetite nucleation from primary colloidal particles is the dominant process at ambient temperature.

In this context, the effect of temperature $\left(90^{\circ} \mathrm{C}\right)$, the presence of citric acid as a retarding additive and the $\mathrm{Fe}^{2+}$ molar fraction $(0.25$ and 0.75$)$ are independently assessed and the main results are 12 
summarized in Figures 4, 5, S2, S3, S6 and S7 and in Table 1. In all these cases, a direct nucleation of magnetite, as described by reaction 1, is measured by dynamic in situ Raman spectroscopy. Herein, the temporal behavior of integrated peak surface area and the FWHM of magnetite, and the temporal behavior of integrated peak surface area for the bending mode of water reveal the same reaction mechanism and only a slight kinetics effect is measured. For example, the partial dissolution of magnetite particles is detected for longer durations at $90^{\circ} \mathrm{C}$ (Figures 4 and S6); this effect is probably due to a slight oxidation process because an inert atmosphere was not controlled in the system. Combined Ostwald ripening process with oxidative dissolution in the investigated system is also not excluded because minor proportion of spinel crystal shape for magnetite were also observed. Another result concerns the retarding effect of citric acid on the second kinetics step (Figures S7 and 5). Here, magnetite-like colloidal particles stabilize at longer durations because a continuous slow increase of the Raman intensity is monitored for three days (Figure S7); but the average particle size monitored by FWHM remains constant. These results indicate that the increase of the magnetite peak is mainly related to the formation of magnetite crystals from residual colloidal particles.

\subsection{Indirect nucleation of magnetite: reaction mechanism and kinetics}

Coprecipitation experimental studies (including bio-mimetic mineralization experiments) have claimed an indirect nucleation process during the formation of magnetite, i.e. the formation of transient phases in the early stages and their subsequent transformation into magnetite $(4,11,15$ 16, 20-26). As above commented, the olation and the oxolation processes are the main sequential colloidal-interacting reactions. During the olation step, various condensate-hydroxylate candidates (or transient phases) such as molecular iron clusters (12), stable pre-nucleation clusters (9) or 13 
metastable iron hydroxide gels $\left(\mathrm{Fe}(\mathrm{OH})_{2}, \mathrm{Fe}(\mathrm{OH})_{3}\right.$ and/or green rusts) $(12,42)$ are suggested. However, the precise structure and chemistry of the transient phases during olation process remains controversial $(9,12,26-30)$. For example, in recent studies, ferrihydrite has been proposed as the most plausible candidate during magnetite co-precipitation under mild conditions, including in living organisms (26-30); but, this mineral phase is already constituted by combined hydroxo and oxo bridges (43). In this context, our time-resolved Raman spectroscopy measurements reveal that green rust $\left(\mathrm{Fe}^{2+}{ }_{3} \mathrm{Fe}^{3+}(\mathrm{OH})_{8} \mathrm{Cl} . \mathrm{nH}_{2} \mathrm{O}\right)$ with a peak at $500 \mathrm{~cm}^{-1}$ and ferric hydroxide gel-like $\left(\mathrm{Fe}(\mathrm{OH})_{3}\right)$ with a weak Raman signal in the region $420-550 \mathrm{~cm}^{-1}$ (see Figure S8) are the transient phases produced during the olation process. They form prior to the nucleation of magnetite, characterized by a peak at $671 \mathrm{~cm}^{-1}$ (oxolation process), when alkaline solution $(4 \mathrm{M}$ of $\mathrm{NaOH})$ is added at a controlled rate $(2.3$ or $12 \mathrm{ml} /$ minute $)$ into a mixed-valent iron solution $\left(0.5 \mathrm{M}\right.$ of $\mathrm{Fe}^{2+}$ and $0.5 \mathrm{M}$ of $\mathrm{Fe}^{3+}$ ), as illustrated in Figure 6 for experiment 8. Based on these time-resolved Raman measurements, the olation process during indirect magnetite nucleation can be written as follows:

$\left[\mathrm{FeCl}_{2}\left(\mathrm{H}_{2} \mathrm{O}\right)_{4}\right]^{+}+3 \mathrm{FeCl}^{+}+4 \mathrm{Na}^{+}+8 \mathrm{OH}^{-}+n \mathrm{H}_{2} \mathrm{O} \Rightarrow \mathrm{Fe}_{3}^{I I} \mathrm{Fe}^{\mathrm{III}}(\mathrm{OH})_{8} \mathrm{Cl}_{2} \mathrm{HH}_{2} \mathrm{O}+4 \mathrm{NaCl}+4 \mathrm{H}_{2} \mathrm{O}$

$\left[\mathrm{FeCl}_{2}\left(\mathrm{H}_{2} \mathrm{O}\right)_{4}\right]^{+}+2 \mathrm{Na}^{+}+3 \mathrm{OH}^{-} \Rightarrow \mathrm{Fe}(\mathrm{OH})_{3}+2 \mathrm{NaCl}+4 \mathrm{H}_{2} \mathrm{O}$

The lifetime or persistence time of green rust depends on the addition rate of the solution. In fact, green rust reaches a maximum Raman intensity and then its transformation (manifested by a decrease of Raman intensity) coincides with the nucleation of magnetite, i.e. with the onset of oxolation (Figures 6 and 7). In this way, the oxolation process can be expressed by the following overall reaction at the particle-particle-solution interfaces between green rust and ferric hydroxide gel-like:

$\mathrm{Fe}_{3}^{\mathrm{II}} \mathrm{Fe}^{\mathrm{III}}(\mathrm{OH})_{8} \mathrm{Cl} . \mathrm{nH}_{2} \mathrm{O}+5 \mathrm{Fe}(\mathrm{OH})_{3} \Rightarrow 3 \mathrm{Fe}_{3} \mathrm{O}_{4}+(11+n) \mathrm{H}_{2} \mathrm{O}+\mathrm{H}^{+}+\mathrm{Cl}^{-}$

Both olation and oxolation processes, expressed by reactions 2 to 4 , are summarized in Figure 7 14 
that shows the temporal behavior of the integrated peak surface areas for aqueous iron, green rust, magnetite and the bending mode of water. Herein, the magnetite nucleation time and lifetime of green rust can be directly related to the rate at which the $\mathrm{NaOH}$ solution is added into the mixedvalent iron solution. The kinetics behavior during the indirect formation of magnetite (reaction 4), is also characterized by an initial fast-parabolic stage taking place during solution addition step, followed by a slow linear stage, probably due to the formation of magnetite from residual colloidal matter. This spectral signal reaches an equilibrium after about $20 \mathrm{~h}$ for both cases. Finally, a hydrophilic-to-hydrophobic change in the suspension is also probed by the temporal behavior of the bending mode of molecular water. Surprisingly, this hydrophilic change in the suspension is also monitored during the formation of green rust and reaches completion after magnetite nucleation (Figure 7).

As described above, the temporal variation of average crystal size for magnetite and transient phases can be directly probed by determining the FWHM parameter. Here, a maximum size for magnetite particles is rapidly reached within 3-5 minutes after nucleation process (Figure 8). Then, very slight variation is detected, indicating that the growth of magnetite crystals is very slow or even inhibited at our investigated conditions. This observation suggests that the temporal increase of intensity of magnetite, monitored after the solution was added, is related to the formation of magnetite from residual colloidal matter. Following the same reasoning, the green rust (transient phase) is characterized by a crystal growth process (i.e. a decrease of its FWHM) after nucleation step. A growth process continues to be detected when this phase starts to be consumed in the system. This observation suggests that this transient phase is transformed by a solid-state transformation or dynamic colloidal interactions, as suggested by reaction 4 . This last mechanism of colloidal assembly was recently proposed in the so-called non-classical crystallization pathway 15 
(e.g. 9, 23, 26, 28). Such assembly mechanisms of amorphous precursors, primary particles, prenucleation species or nanocrystals remain poorly characterized (e.g. 23, 26).

\subsection{Particle size and agglomeration state}

Average particle size, agglomeration state and shape of crystals/particles are fundamental textural properties for the industrial applications of magnetite (e.g. 1-2). In the present study, some conventional measurements by FESEM imaging and powdered XRD are performed in order to determine the average size of magnetite crystals and their shape and agglomeration state. FESEM images at high magnification without metallic coating reveal small rounded nanoparticles $(5<\mathrm{z}<20 \mathrm{~nm})$ with slight agglomeration state for the direct nucleation of magnetite (see Figure 9 and also Figure S9 and S10). In fact, higher particle size and higher agglomeration state are clearly observed for indirect nucleation of magnetite (see Figure 9 and also Figures S9-S11). FESEM results agree with Rietveld refinements of XRD patterns and some raw XRD data are displayed in Figure 9 (see also Figure S12). Here, the domain coherent average size of magnetite nanoparticles obtained from direct nucleation varies from 7 to $9 \mathrm{~nm}$. Conversely, higher domain coherent average size is determined for magnetite nanoparticles obtained from indirect nucleation (14 nm) (see Table 1). As described previously, the temporal behavior of FWHM of magnetite strongest Raman peak is a qualitative indicator of crystal size and the results agree well with FESEM images and Rietveld refinement of XRD data, as illustrated in Figure S13. Here, the probed higher values $\left(54-58 \mathrm{~cm}^{-1}\right)$ for the direct nucleation of magnetite indicate smaller crystal size with respect to probed values $\left(53-55 \mathrm{~cm}^{-1}\right)$ for the indirect nucleation of magnetite. In summary, direct nucleation of magnetite allows the production of smaller rounded nanoparticles with low agglomeration state. This material might have a high potential on the fabrication of ferrofluids and other already investigated 16 
applications that depend on magnetite particle size (e.g. 1). The simple co-precipitation method we have used here could be extrapolated to industrial scale and the control of inert conditions $\left(\mathrm{O}_{2}\right.$-free $)$ is not necessary. Finally, if higher crystal sizes of magnetite are required, a simple heat-ageing step could be performed. For example, when magnetite nanoparticles obtained from direct nucleation are heated at $120^{\circ} \mathrm{C}$ in the mother solution, two well-distinct crystal populations with larger particle size are obtained after $48 \mathrm{~h}$, a dominant proportion of nanoparticles $(20<\mathrm{z}<30 \mathrm{~nm})$ (Figure S14) and a minor proportion of well faceted crystals with octahedral prism shape of magnetite $(\mathrm{z}>90 \mathrm{~nm})$ (Figure S15).

\section{Conclusion}

The present study reports novel and complementary insights on the direct and indirect nucleation of magnetite nanoparticles monitored by Raman spectroscopy in real-time. Herein, peak position, integrated peak surface area and full width at half maximum (FWHM) for iron species, transient condensate phases, magnetite and bending mode of water are fundamental parameters to identify the reaction mechanisms and quantify the kinetics of magnetite formation from ionic solutions. Moreover, the bending mode of water is used to probe a hydrophilic-to-hydrophobic change in suspension during magnetite formation.

In this way, direct nucleation of magnetite nanoparticles is observed when a mixed-valent iron solution is added at controlled flow rate into a concentrated alkaline solution $(\mathrm{pH}=14)$. In this case, olation and exolation processes occur simultaneously and almost instantaneously leading to the formation of dark colloidal magnetite-like particles with a broad Raman band between 674 and 678

$\mathrm{cm}^{-1}$ and detected after 3 to 7 minutes, depending on the rate of addition of the solution (2.3 and $12 \mathrm{ml} / \mathrm{min}$ ). The strongest Raman peak of magnetite rapidly stabilizes at $673 \mathrm{~cm}^{-1}$. Temperature 17 
(ambient temperature and $90^{\circ} \mathrm{C}$ ), presence of citric acid as retarding agent and $\mathrm{Fe}^{2+}$ molar fraction (in the range 0.25-0.75) reveal insignificant change on the reaction mechanism (reaction 1), and slight changes on the kinetics. Conversely, indirect nucleation of magnetite is monitored when the addition-solution is inversed, i.e. when alkaline solution is added at controlled flow rate into a mixed-valent iron solution (initial $\mathrm{pH} \approx 1$ ). This scenario implies a progressive increase of the $\mathrm{pH}$ from 1 to 14 during addition time. In this case, the monitored reaction mechanisms and kinetics measured with dynamic in situ Raman spectroscopy are more complex. Firstly, an olation process occurs, i.e. the formation of hydroxo bridges is probed by the transient formation of green rust and ferric hydroxide gel. The kinetics of this reaction stage is proportional to the addition rate of the solution. Secondly, the green rust and ferric hydroxide gel interact, probably, via particle-particlesolution interaction or via colloidal assembly leading to the nucleation of magnetite. The kinetics of this oxolation process is characterized by an initial fast hyperbolic stage, followed by a slow linear behavior as described by second-order kinetic models. This latter kinetic step with a spectral equilibration occurs after about $20 \mathrm{~h}$. In contrast, the growth of magnetite crystals is very slow or even inhibited because the FWHM reaches a maximum value only some minutes after magnetite nucleation.

Mechanisms of direct or indirect nucleation of magnetite are proposed in the literature (e.g. 13), but to the best of our knowledge, this is the first time that both pathways are monitored in real time. Our results demonstrate that dynamic in situ Raman spectroscopy, combined with conventional ex situ characterization of solids and solutions, provides basic knowledge on the classical and nonclassical crystallization pathways in homogeneous or heterogeneous systems, as already demonstrated in previous studies on carbonates and phosphates (34-37). Moreover, our results suggest that amorphous transient phases during direct and indirect nucleation of magnetite from 18 
ionic solutions do not exist or that such phases do not show a specific Raman signature. 


\section{Acknowledgements}

The authors acknowledge funding from the French National Centre for Scientific Research (CNRS) and the Université Grenoble Alpes (UGA). The FUNMIN project funded an additional Raman probe for in situ and ex situ measurements in suspensions and powders. 


\section{Appendix A. Supplementary data}

Supplementary material (one Table and 15 additional figures) are provided in the online version, at 


\section{References}

(1) Mosayebi, J.; Kiyasatfar, M.; Laurent, S. Synthesis, Functionalization, and Design of Magnetic Nanoparticles for Theranostic Applications. Adv. Healthcare Mater. 2017, 1700306.

(2) Usman, M.; Byrne, J. M.; Chaudhary, A.; Orsetti, S.; Hanna, K.; Ruby, C. A. Kappler, C. A.; Haderlein, S. B. Magnetite and Green Rust: Synthesis, Properties, and Environmental Applications of Mixed-Valent Iron Minerals. Chem. Rev. 2018, 118, 3251-3304.

(3) Baumgartner, J.; Carillo, M. A. ; Eckes, K. E.; Werner, P.; Faivre, D. Biomimetic Magnetite Formation: From Biocombinatorial Approaches to Mineralization Effects. Langmuir 2014, 30, 2129-2136.

(4) Mirabello, G.; Lenders J. J. M.; Sommerdijk, N. A. J. M. Bioinspired Synthesis of Magnetite Nanoparticles. Chem. Soc. Rev. 2016, 45, 5085-5106.

(5) Han, X.; Tomaszewski, E. J.; Sorwat, J.; Pan, Y.; Kappler, A.; Byrne, J. M. Effect of Microbial Biomass and Humic Acids on Abiotic and Biotic Magnetite Formation. Environ. Sci. Technol. 2020, 54, 7, 4121-4130.

(6) Nozawa, J.; Tsukamoto, K.; van Enckevort, W.; Nakamura, T.; Kimura, Y.; Miura, H.; Satoh, H.; Nagashima, K.; Konoto, M. Magnetite 3D Colloidal Crystals Formed in the Early Solar System 4.6 Billion Years Ago. J. Am. Chem. Soc. 2011, 133, 8782-8785.

(7) Kirschvink, J. L.; Gould, J. L. Biogenic Magnetite as a Basis for Magnetic Field Detection in Animals. BioSystems 1981, 13, 181-201. 
(8) Mann, S.; Frankelt, R. B.; Blakemore, R. P. Structure, morphology and crystal growth of bacterial magnetite. Nature 1984, 310, 405-407.

(9) Scheck, J.; Wu, B.; Drechsler, M.; Rosenberg, R.; Van Driessche, A. E. S.; Stawski, T. M.;

Gebauer, D. The Molecular Mechanism of Iron(III) Oxide Nucleation. J. Phys. Chem. Lett. 2016, 7, 3123-3130.

Karthika, S.; Radhakrishnan, T. K.; Kalaichelvi, P. A Review of Classical and Nonclassical Nucleation Theories. Cryst. Growth Des. 2016, 16, 6663-6681.

Ahn, T.; Kim, J. H.; Yang, H. M.; Lee, J. W.; Kim, J. D. Formation Pathways of Magnetite Nanoparticles by Coprecipitation Method. J. Phys. Chem. C 2012, 116, 6069-60.

Jolivet, J. P. ; Chanéac, C. ; Tronc E. Iron oxide chemistry. From molecular clusters to extended solid networks. Chem. Commun. 2004, 481-487.

$$
\text { De Yoreo, J. More than one pathway. Nature Materials 2013, 12, 284-285. }
$$

by chemical precipitation method. Journal of Physics: Conference Series 2009, 012041.

Abou-Hassan, A. ; Sandre, O.; Cabuil, V. Microfluidic Devices for Synthesis of Iron Oxide Nanoparticles. in Microfluidic Devices in Nanotechnology: Applications, C.S.S.R. Kumar, Editor 2010, John Wiley \& Sons, Hoboken NJ, 323-360. Sacchi Peternele, W.; Monge Fuentes, V.; Fascineli, M. L.; Rodrigues da Silva, J.; Carvalho Silva, R.; Madeira Lucci, C.; Bentes de Azevedo, R. Experimental Investigation 
of the Coprecipitation Method: An Approach to Obtain Magnetite and Maghemite Nanoparticles with Improved Properties. J. Nanomaterials 2014 doi.org/10.1155/2014/682985. Reichel, V. Kovács, A.; Kumari, M.; Bereczk-Tompa, E.; Schneck, E.; Diehle, P. Pósfai, M.; Hirt, A. M.; Duchamp, M.; Dunin-Borkowski, R. E.; Faivre, D. Single crystalline superstructured stable single domain magnetite nanoparticles. Scientific Reports 2017, DOI: $10.1038 /$ srep45484.

Norfolk, L.; Rawlings, A. E.; Bramble, J. P.; Ward, K.; Francis, N.; Waller, R.; Bailey, A.; Staniland, S. S. Macrofluidic Coaxial Flow Platforms to Produce Tunable Magnetite Nanoparticles: A Study of the Effect of Reaction Conditions and Biomineralisation Protein Mms6. Nanomaterials 2019, 9, 1729; doi:10.3390/nano9121729.

Daoush, W.M. Co-Precipitation and Magnetic Properties of Magnetite Nanoparticles for Potential Biomedical Applications. J. Nanomed Res. 2017, 5(3): 00118. DOI: 10.15406/jnmr.2017.05.00118.

Jos J. M. Lenders, J. J. M.; Altan, C. L.; Bomans, P. H. H.; Arakaki, A.; Bucak, S.; de With, G.; Sommerdijk, N. A. J. M. A Bioinspired Coprecipitation Method for the Controlled Synthesis of Magnetite Nanoparticles. Cryst. Growth Des. 2014,14, 5561-5568.

$$
\text { Dang, F.; Enomoto, N.; Hojo, J.; Enpuku, K. Synthesis of monodispersed cubic }
$$
magnetite particles through the addition of small amount of $\mathrm{Fe}^{3+}$ into $\mathrm{Fe}(\mathrm{OH})_{2}$ suspension. J. Cryst. Growth 2010, 312, 1736-1740. 

from a disordered ferrihydrite-derived precursor. Faraday Discuss. 2015, 179, 215-225.

Mirabello, G.; Ianiro, A.; Bomans, P. H. H.; Yoda, T.; Arakaki, A.; Friedrich, H.; de With, G.; Sommerdijk, N. A. J. M. Crystallization by particle attachment is a colloidal assembly process. Nature Materials 2020, 19, 391-396.

Kirillov, V. L.; Balaev, D. A.; Semenov, S. V.; Shaikhutdinov, K., A.; Martyanov, O. N. Size control in the formation of magnetite nanoparticles in the presence of citrate ions. Mater. Chem. Phys. 2014, 145, 75-81.

Milosevic, I.; Warmont, F.; Lalatonne, Y.; Motte, L. Magnetic metrology for iron oxide nanoparticle scaled-up synthesis. $R S C A d v$. 2014, 4, 49086-49089.

(26) Baumgartner, J. ; Dey, A. ; Bomans, P. H. H. ; Le Coadou, C. ; Fratzl, P. ; Sommerdijk, N. A. J. M. ; Faivre, D. Nucleation and growth of magnetite from solution. Nature Materials 2013, 12, 310-314.

Baumgartner, J. ; Bertinetti, L. ; Widdrat, M. ; Hirt, A. M. ; Faivre, D. Formation of Magnetite Nanoparticles at Low Temperature: From Superparamagnetic to Stable Single Domain Particles. Plos One 2013, 8, e57070.

LaGrow, A. P.; Besenhard, M. O.; Hodzic, A.; Sergides, A.; Bogart, L. K.; Gavriilidis, A.; Thanh, N. T. K. Unravelling the growth mechanism of the coprecipitation of iron oxide nanoparticles with the aid of synchrotron X-Ray diffraction in solution. Nanoscale 2019, 11, 6620-6628. 

W.; Bente, K.; Fratzl, P.; Faivre, D. J. Phys. Chem. Lett. 2017, 8, 1132-1136.

Lenders, J. J. M.; Mirabello, G.; Sommerdijk, N. A. J. M. Bioinspired magnetite synthesis via solid precursor phases. Chem. Sci. 2016, 7, 5624-5634.

Park, B. C.; Jiung Cho, J.; Kim, M. S.; Ko, M. J.; Pan, L.; Na, J. Y.; Kim, Y. K. Strategy to control magnetic coercivity by elucidating crystallization pathway-dependent microstructural evolution of magnetite mesocrystals. Nature Communications 2020, 11, 298, doi.org/10.1038/s41467-019-14168-0.

Sun, S.; Gebauer, D.; Cölfen, H. Alignment of Amorphous Iron Oxide Clusters: A Non-Classical Mechanism for Magnetite Formation. Angew. Chem. Int. Ed. 2017, 56, $4042-4046$.

Reichel, V.; Kovács, A.; Kumari, M. Bereczk-Tompa, E.; Schneck, E.; Diehle, P.; Pósfai, M.; Hirt, A. M.; Duchamp, M.; Dunin-Borkowski, R. E.; Faivre, D. Single crystalline superstructured stable single domain magnetite nanoparticles. Scientific Reports 2017, 7:45484; DOI: 10.1038/srep45484.

Montes-Hernandez, G. ; Renard, F. Time-resolved in situ Raman spectroscopy of the nucleation and growth of siderite, magnesite and calcite and their precursors. Cryst. Growth Des. 2016, 16, 7218-7230.

Montes-Hernandez, G.; Renard, F.; Auzende, A. L. ; Findling, N. Amorphous calcium-magnesium carbonate (ACMC) accelerates dolomitization at room temperature 
under abiotic conditions. Cryst. Growth Des. 2020, 20, 1434-1441.

Montes-Hernandez, G.; Renard, F. Nucleation of Brushite and Hydroxyapatite from Amorphous Calcium Phosphate Phases Revealed by Dynamic in situ Raman Spectroscopy. J. Phys. Chem. C 2020, 124, 15302-15311.

Montes-Hernandez, G. ; Bah, M. ; Renard, F. Mechanism of the formation of engineered magnesite: A useful mineral to mitigate $\mathrm{CO} 2$ industrial emissions. J. CO2 Util. 2020, 35, 272-276.

Taut, T.; Kleeberg, R.; Bergmann, J. The new Seifert Rietveld program BGMN and its application to quantitative phase analysis. Materials Science (Bulletin of the Czech and Slovak Crystallographic Association) 1998, 5, 55-64.

Kanno, H.; Hiraishi, J. Raman Study of Aqueous Solutions of Ferric Nitrate, Ferrous Chloride and Ferric Chloride in the Glassy State. J. Raman Spectrosc. 1982, 12, 224-227.

Seki, T.; Chiang, K. Y.; Yu, C. C.; Yu, X.; Okuno, M.; Hunger, J.; Nagata, Y.; Bonn, M. The Bending Mode of Water: A Powerful Probe for Hydrogen Bond Structure of Aqueous Systems. J. Phys. Chem. Lett. 2020, 11, 8459-8469.

Gouadec, G. ; Colomban, P. Raman Spectroscopy of nanomaterials: How spectra relate to disorder, particle size and mechanical properties. Prog. Cryst. Growth Charact. Mater. 2007, 53, 1-56. Montes-Hernandez, G.; Beck, P.; Renard, F.; Quirico, E.; Lanson, B.; Chiriac, R.; 
Findling, N. Fast precipitation of acicular goethite from ferric hydroxide gel under moderate temperature (30 and 70 C degrees). Cryst. Growth Des. 2011, 11 2264-2272.

Manceau, A.; Drits, V.A. Local structure of ferrihydrite and feroxyhite by EXAFS spectroscopy. Clay Minerals 1993, 28, 165-184. 
Table 1. List of experiments with time-lapse Raman spectroscopy for precipitation of magnetite at room temperature and $90^{\circ} \mathrm{C}$, and influence of $\mathrm{Fe}^{2+}$ molar fraction. Mother solutions: $4 \mathrm{M}$ of $\mathrm{NaOH}$, $1 \mathrm{M}$ of $\mathrm{Fe}^{3+}$ from hydrated $\mathrm{FeCl}_{3}$ and $1 \mathrm{M}$ of $\mathrm{Fe}^{2+}$ from hydrated $\mathrm{FeCl}_{2}$. Two different systems: 1) addition of mixed-valent iron solution into $\mathrm{NaOH}$ solution (constant $\mathrm{pH} 14$ ); 2) addition of $\mathrm{NaOH}$ solution into mixed-valent iron solution ( $\mathrm{pH}$ varies from 1 to 14 ).

\begin{tabular}{|c|c|c|c|c|c|c|}
\hline Exp. & $\begin{array}{c}\text { Temperature } \\
\left({ }^{\circ} \mathrm{C}\right)\end{array}$ & $\begin{array}{c}\mathrm{Fe}^{2+} \text { volume } \\
\text { fraction }^{\mathrm{a}}\end{array}$ & $\begin{array}{c}\text { Addition rate } \\
\text { (ml/minute) }\end{array}$ & Duration & $\begin{array}{c}\text { Reaction } \\
\text { mechanism }\end{array}$ & $\begin{array}{c}\text { Average size of } \\
\text { MNPs }\end{array}$ \\
\hline 1 & 26 & 0.5 & $\begin{array}{c}2.3 \\
\text { Iron solution-into } \mathrm{NaOH}\end{array}$ & $19 \mathrm{~h}$ & $\begin{array}{c}\text { Direct } \\
\text { nucleation }\end{array}$ & $9 \mathrm{~nm}$ (from XRD) \\
\hline 2 & 25 & 0.5 & $\begin{array}{c}12 \\
\text { Iron solution into } \mathrm{NaOH}\end{array}$ & $43 \mathrm{~h}$ & $\begin{array}{c}\text { Direct } \\
\text { nucleation }\end{array}$ & $8 \mathrm{~nm}$ (from XRD) \\
\hline 3 & 90 & 0.5 & $\begin{array}{c}2.3 \\
\text { Iron solution into } \mathrm{NaOH}\end{array}$ & $50 \mathrm{~h}$ & $\begin{array}{c}\text { Direct } \\
\text { nucleation }\end{array}$ & $8 \mathrm{~nm}$ (from XRD) \\
\hline 4 & 26 & 0.5 & $\begin{array}{l}12 \\
\text { Iron solution into } \mathrm{NaOH} \\
\text { in presence of citric acid }\end{array}$ & $70 \mathrm{~h}$ & $\begin{array}{c}\text { Direct } \\
\text { nucleation }\end{array}$ & $7 \mathrm{~nm}$ (from XRD) \\
\hline 5 & 26 & 0.75 & $\begin{array}{c}12 \\
\text { Iron solution into } \mathrm{NaOH}\end{array}$ & $20 \mathrm{~h}$ & $\begin{array}{c}\text { Direct } \\
\text { nucleation }^{\mathrm{b}}\end{array}$ & not measurement \\
\hline 6 & 27 & 0.25 & $\begin{array}{l}12 \\
\text { Iron solution into } \mathrm{NaOH}\end{array}$ & $72 \mathrm{~h}$ & $\begin{array}{c}\text { Direct } \\
\text { nucleation }\end{array}$ & not measurement \\
\hline 7 & 25 & 0.5 & $\begin{array}{c}2.3 \\
\mathrm{NaOH} \text { into iron solution }\end{array}$ & $70 \mathrm{~h}$ & $\begin{array}{c}\text { Indirect } \\
\text { nucleation } \\
\text { (green rust as } \\
\text { transient phase) }\end{array}$ & $14 \mathrm{~nm}$ (from RXD) \\
\hline 8 & 26 & 0.5 & $\begin{array}{c}12 \\
\mathrm{NaOH} \text { into iron solution }\end{array}$ & $19 \mathrm{~h}$ & $\begin{array}{c}\text { Indirect } \\
\text { nucleation } \\
\text { (green rust as } \\
\text { transient phase) }\end{array}$ & $14 \mathrm{~nm}$ (from XRD) \\
\hline 9 & 25 & $\begin{array}{c}0 \\
\text { Ref. } \mathrm{Fe}^{3+}\end{array}$ & $\begin{array}{c}2.3 \\
\text { Iron solution into } \mathrm{NaOH}\end{array}$ & 48 & Not applicable & Goethite phase \\
\hline 10 & 26 & $\begin{array}{c}1 \\
\text { Ref. } \mathrm{Fe}^{2+}\end{array}$ & $\begin{array}{c}2.3 \\
\text { Iron solution into } \mathrm{NaOH}\end{array}$ & 72 & Not applicable & $\begin{array}{l}\text { Multi-phasic: } \\
\text { goethite, GR, } \\
\text { Magnetite }\end{array}$ \\
\hline
\end{tabular}

a: $\mathrm{V}_{\mathrm{Fe} 2+} /\left(\mathrm{V}_{\mathrm{Fe} 2+}+\mathrm{V}_{\mathrm{Fe} 3+}\right)$; b: direct nucleation is dominant process, but, small Raman signature for green rust-like is also detected in the first hour of experiment; Ref. $\mathrm{Fe}^{+3}$ : single ferric iron solution; Ref. $\mathrm{Fe}^{2+}$ : single ferrous iron solution without control of inert atmosphere during experiment; GR: green rust. 

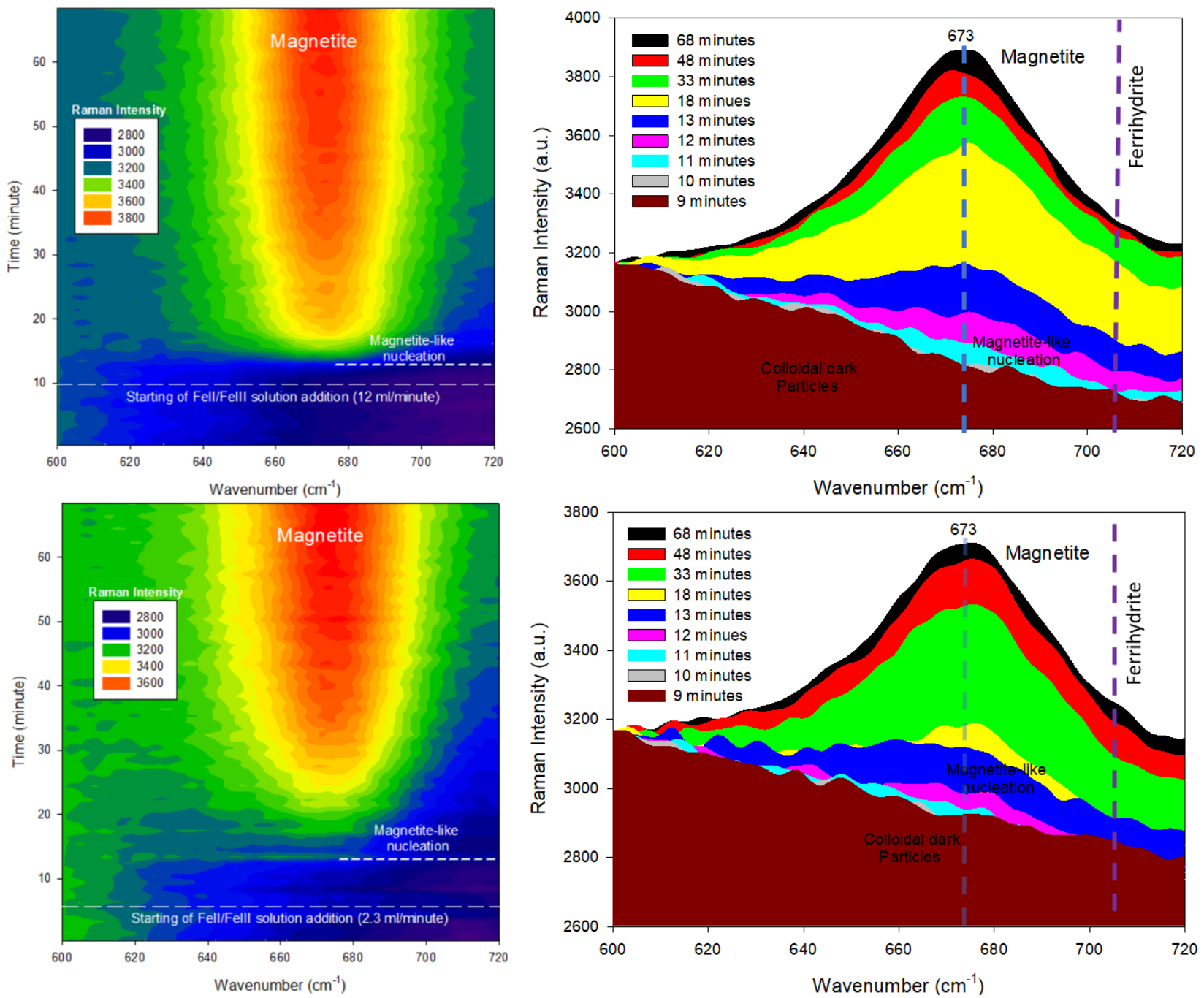

Figure 1. Left: Time-lapse Raman spectroscopy monitoring of direct nucleation of magnetite in experiments 1 and 2 (raw Raman spectra between 0 and 70 minutes). Right: Selected spectra showing the evolution of the magnetite peak (shape, intensity and position) at different times. 

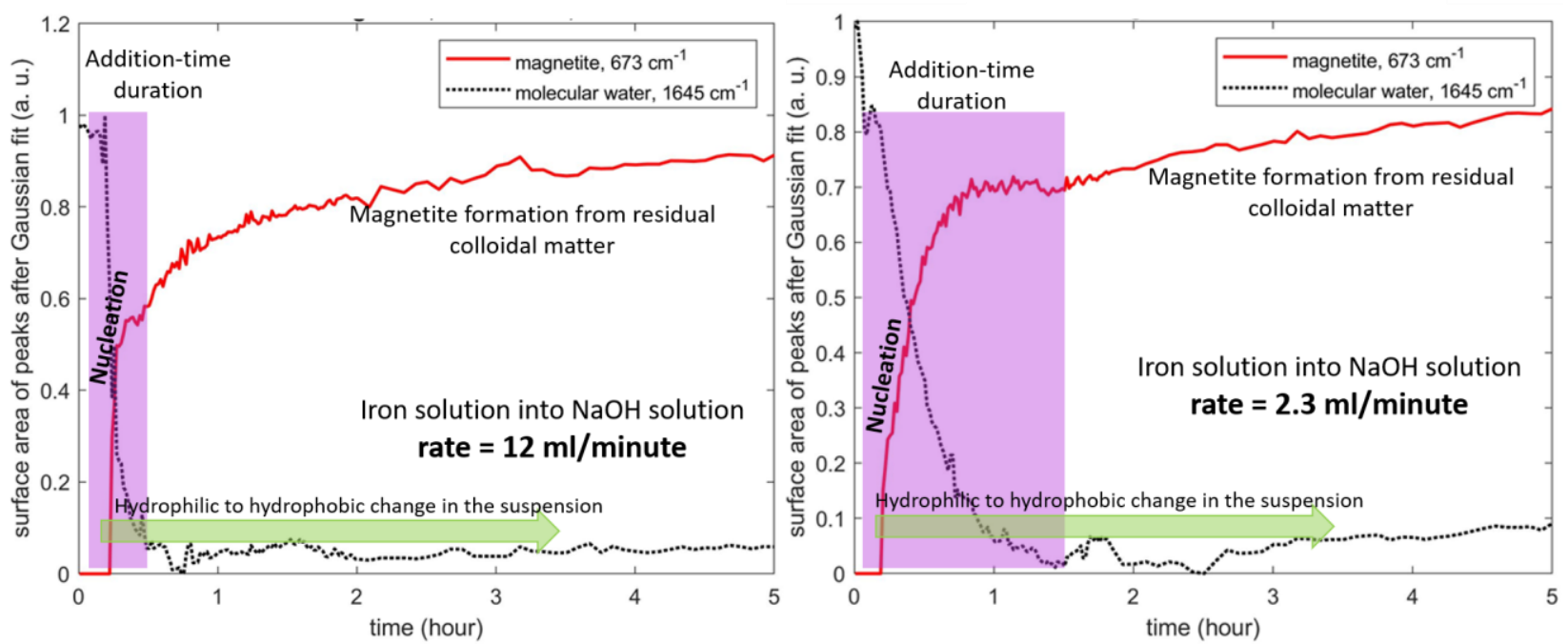

Figure 2. Kinetics behavior during the direct formation of magnetite at room temperature from integrated peak surface areas versus time (experiments 1 and 2). For the two rates of solution investigated, a hyperbolic kinetics behavior is measured that is characterized by a fast-kinetic step during which the direct nucleation of magnetite occurs (reaction 1). Magnetite nucleation is strongly correlated with a hydrophilic-to-hydrophobic change in the suspension as probed by the bending mode of water in the interacting suspension. For longer reaction times, a slow kinetics step is measured until the end of experiment. The slow progressive increase of Raman intensity is related to magnetite formation from residual colloidal particles. 

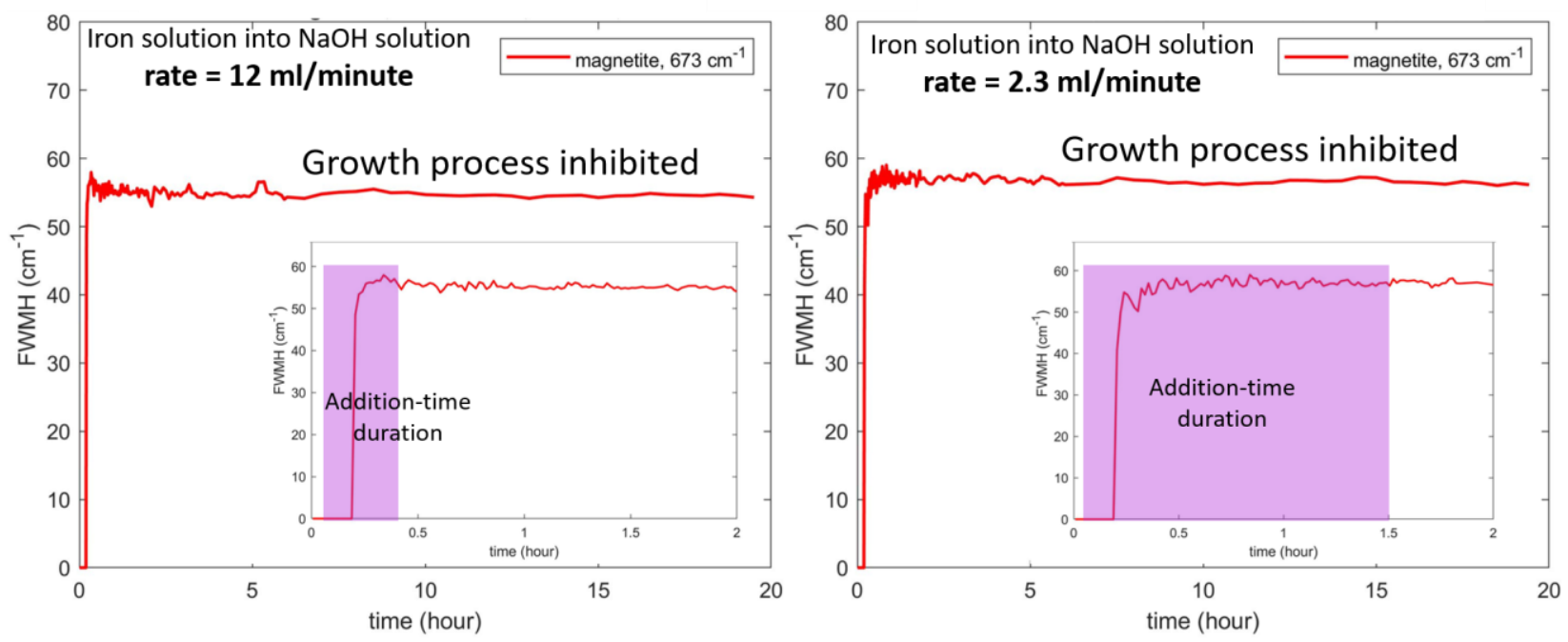

Figure 3. Temporal behavior of FWHM parameter for direct magnetite formation (reaction 1) at room temperature and for two different rates of solution addition (experiments 1 and 2 in Table 1). Assuming that the crystal size is proportional to 1/FWHM, here the crystal growth process of magnetite crystals is either inhibited or significantly slowed down under the investigated durations because the FWHM for magnetite reaches rapidly a maximum value and then remains constant $\left(57 \mathrm{~cm}^{-1} \pm 2\right)$. 

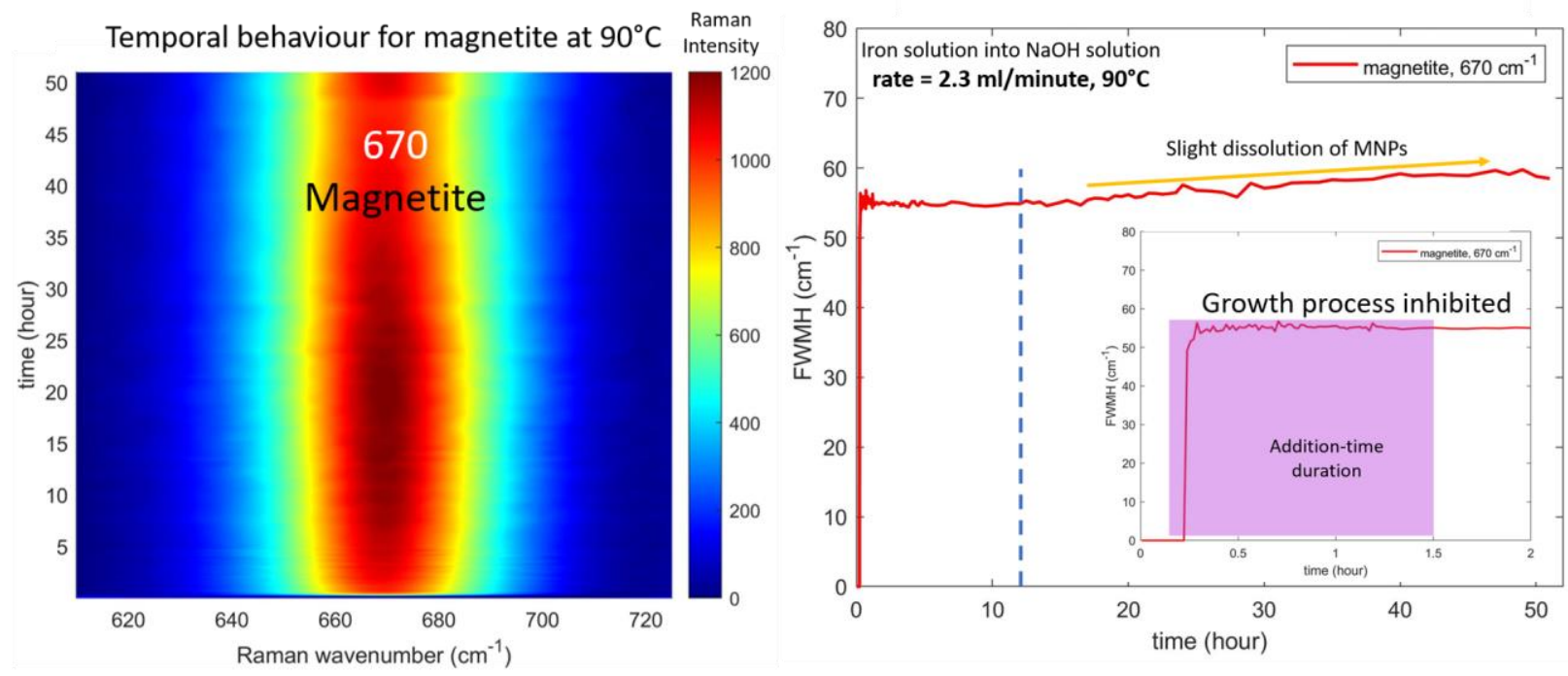

Figure 4. Left: Zoom of time-lapse Raman spectroscopy monitoring of the direct formation of magnetite at $90^{\circ} \mathrm{C}$ in experiment 3 (Table 1). Right: Temporal behavior of FWHM parameter for magnetite peaks (experiments 3). Assuming that the crystal size is proportional to 1/FWHM, here the crystal growth process of magnetite crystals is inhibited or very slow in the first two hours because the FWHM of magnetite remains constant $\left(55 \mathrm{~cm}^{-1} \pm 2\right)$ (inset). After about 10 hours, the increase of FWHM indicates the partial dissolution of magnetite crystals. 

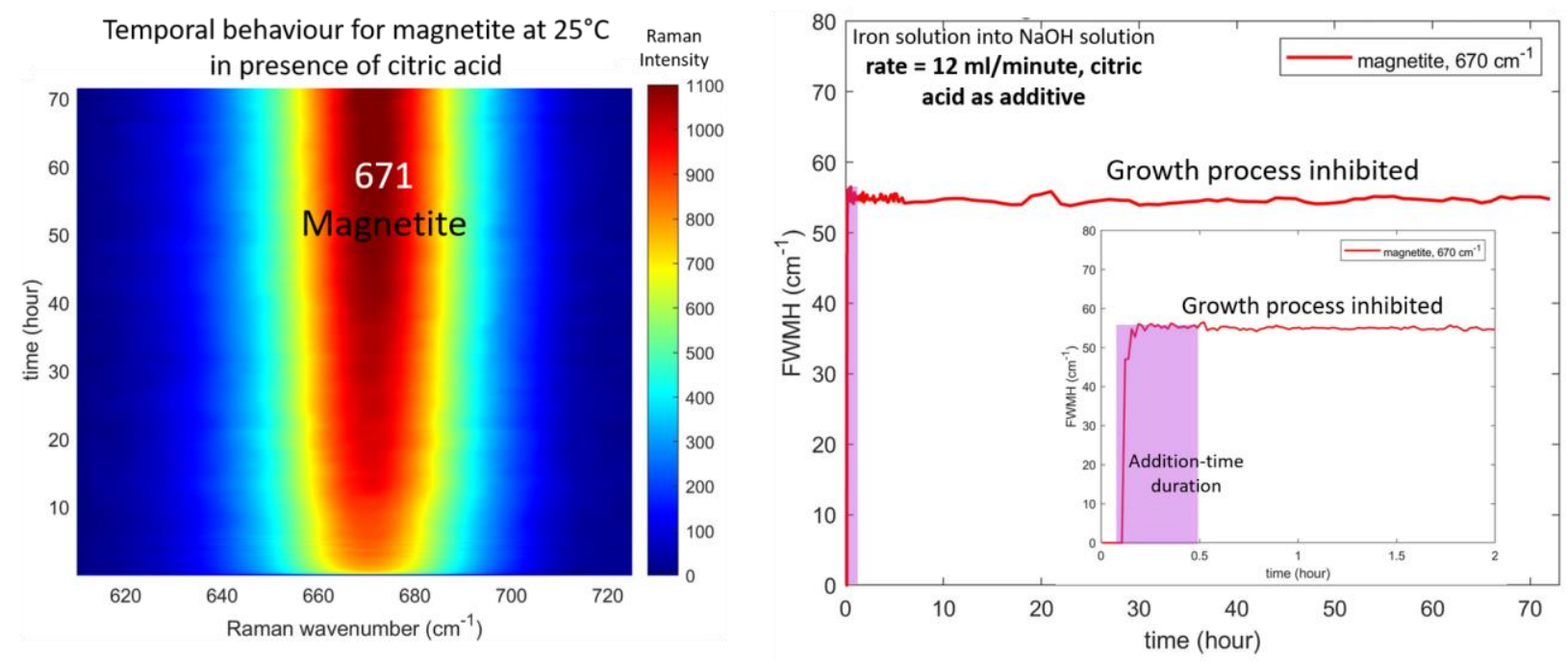

Figure 5. Left: Zoom of time-lapse Raman spectroscopy monitoring of the direct formation of magnetite at room temperature in presence of citric acid in experiment 4 (Table 1). Right: Temporal behavior of FWHM parameter for magnetite peaks (experiments 4). Assuming that the crystal size is proportional to $1 / \mathrm{FWHM}$, here the crystal growth process of magnetite crystals is inhibited or very slow, reaching a constant value in the first 30 minutes (inset). Then, the FWHM of magnetite remains constant $\left(56 \mathrm{~cm}^{-1} \pm 2\right)$. 

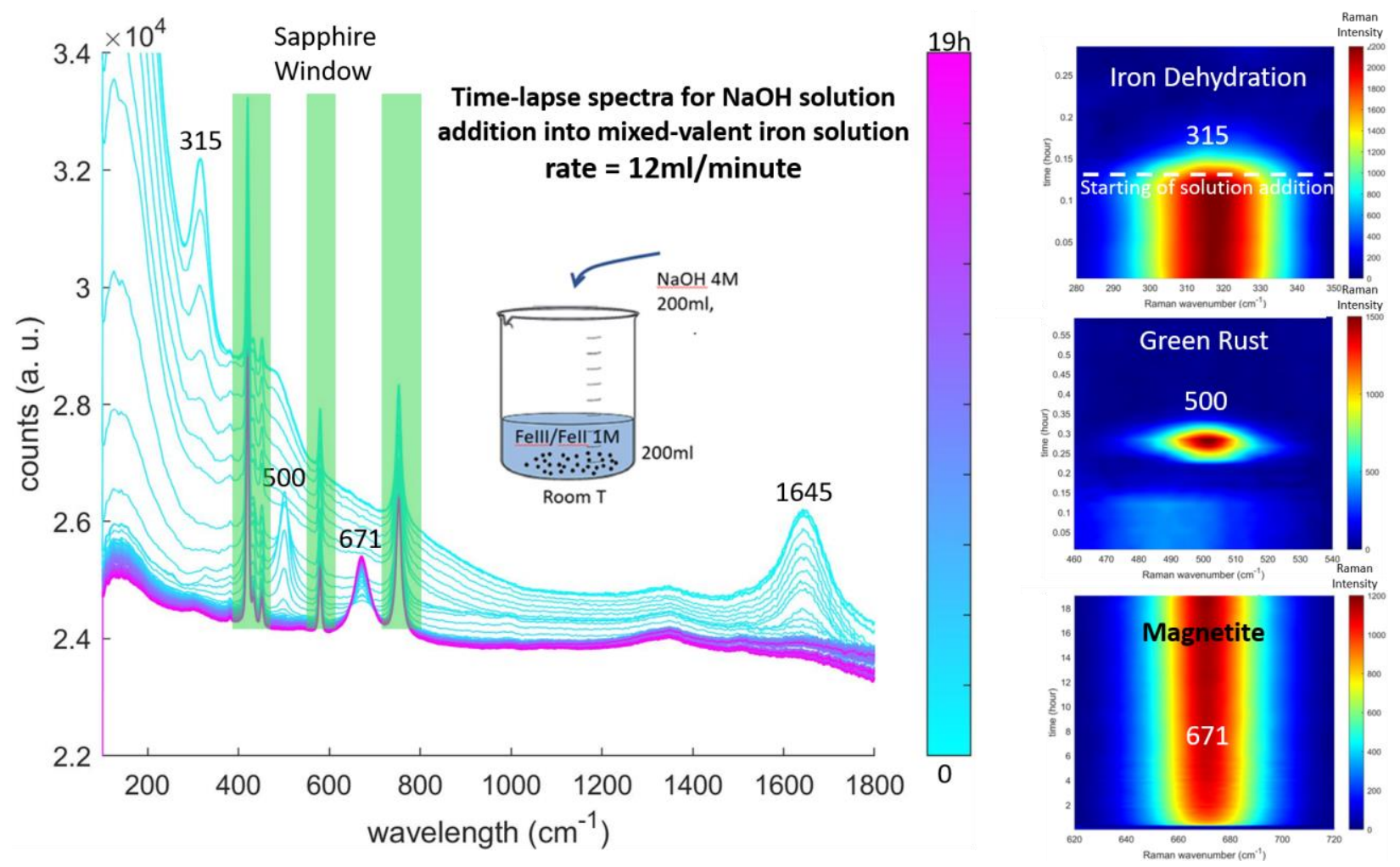

Figure 6. Left: Time-lapse spectra for $\mathrm{NaOH}$ solution addition into mixed-valent iron solution in experiment 8 (addition rate $=12 \mathrm{ml} /$ minute, ambient temperature and initial $\mathrm{pH} 1$ ). Indirect nucleation of magnetite peaking at $671 \mathrm{~cm}^{-1}$ is detected in the Raman spectra. Here, green rust peaking at $500 \mathrm{~cm}^{-1}$ is mainly a transient phase. Initial hydration state of mixed-valent iron solution is characterized by a Raman signature peaking at $315 \mathrm{~cm}^{-1}$ and a broad band peaking at $485 \mathrm{~cm}^{1}$, both assigned to ferric species (see Table S1 and Figure S5). The temporal decrease of the bending mode of molecular water peaking at $1645 \mathrm{~cm}^{-1}$ in the dispersed suspensions reveals a change in the system from hydrophilic to hydrophobic. Right: Zoom of time-lapse Raman spectroscopy monitoring of iron dehydration, green rust transient step and magnetite formation (stable phase). 

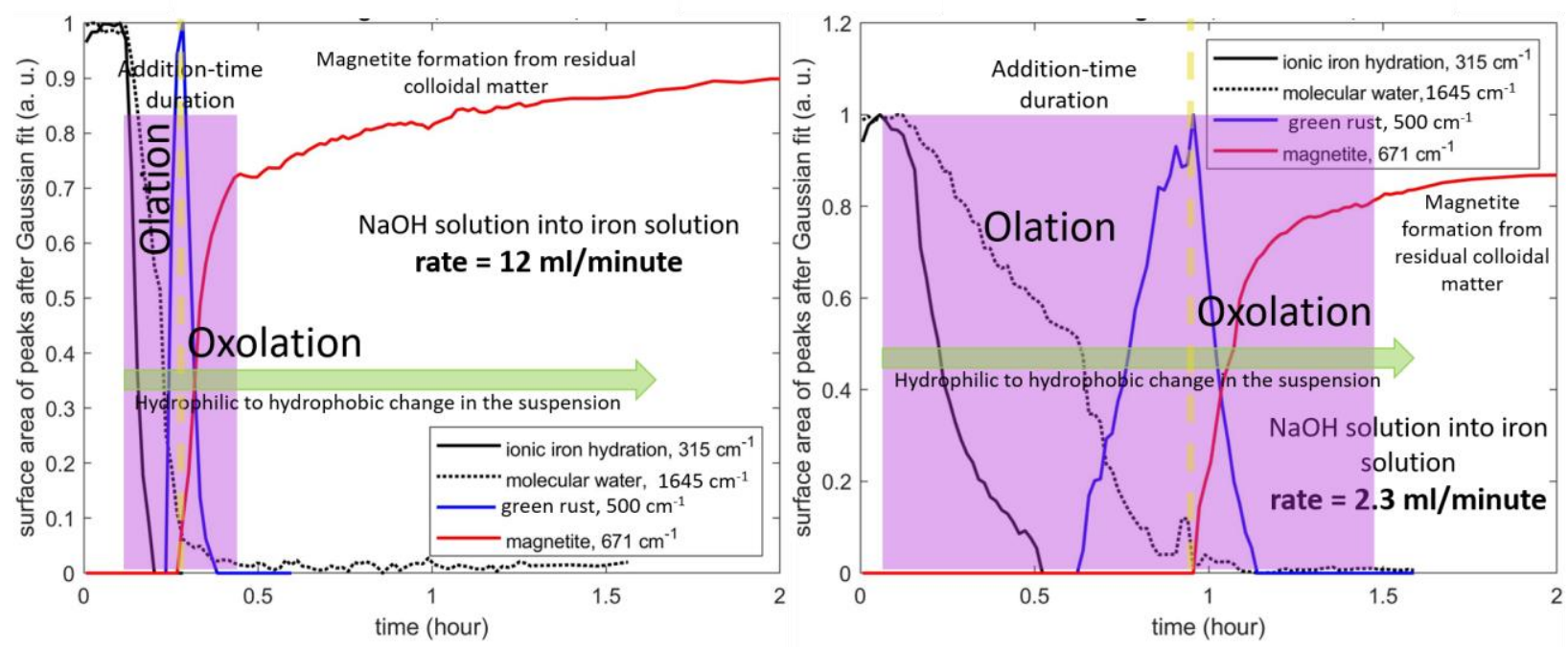

Figure 7. Kinetics behavior during indirect formation of magnetite at ambient temperature from integrated peak surface areas versus time (experiments 7 and 8). Raman spectroscopy reveals a complex reaction mechanisms and kinetics. Firstly, iron dehydration and precipitation of green rust as transient phase are related to the olation process, i.e. the formation of hydroxo bridges accompanied by the expulsion of molecular water (reaction 2). Secondly, green rust and available ferric iron (ions or colloids) react to nucleate magnetite via an oxolation process, i.e. the formation of oxo bridges accompanied with expulsion of hydroxylated water (reaction 4). The nucleation time of magnetite and hydrophilic-to-hydrophobic change in the suspension is also measured by the temporal behavior of the bending mode of molecular water. Here, both correlated processes are directly proportional to addition rate of solutions. 

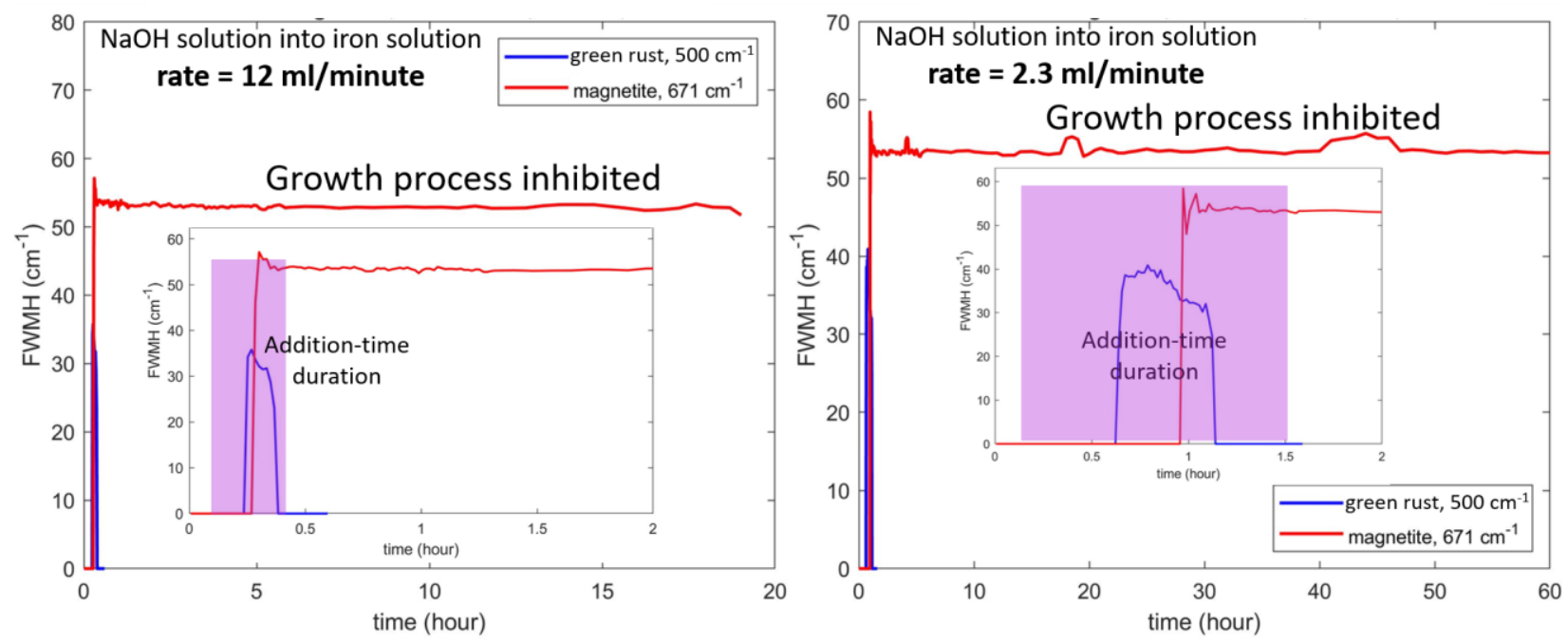

Figure 8. Temporal behavior of FWHM parameter during the indirect formation of magnetite (reactions 2 and 3) at ambient temperature and for two different rates of solution addition (experiments 7 and 8 in Table 1). Assuming that the crystal size is proportional to 1/FWHM, here the crystal growth process of magnetite crystals is inhibited or slowed down at the investigated durations because the FWHM for magnetite reaches rapidly a maximum value and then remains constant $\left(53 \mathrm{~cm}^{-1} \pm 2\right)$. 

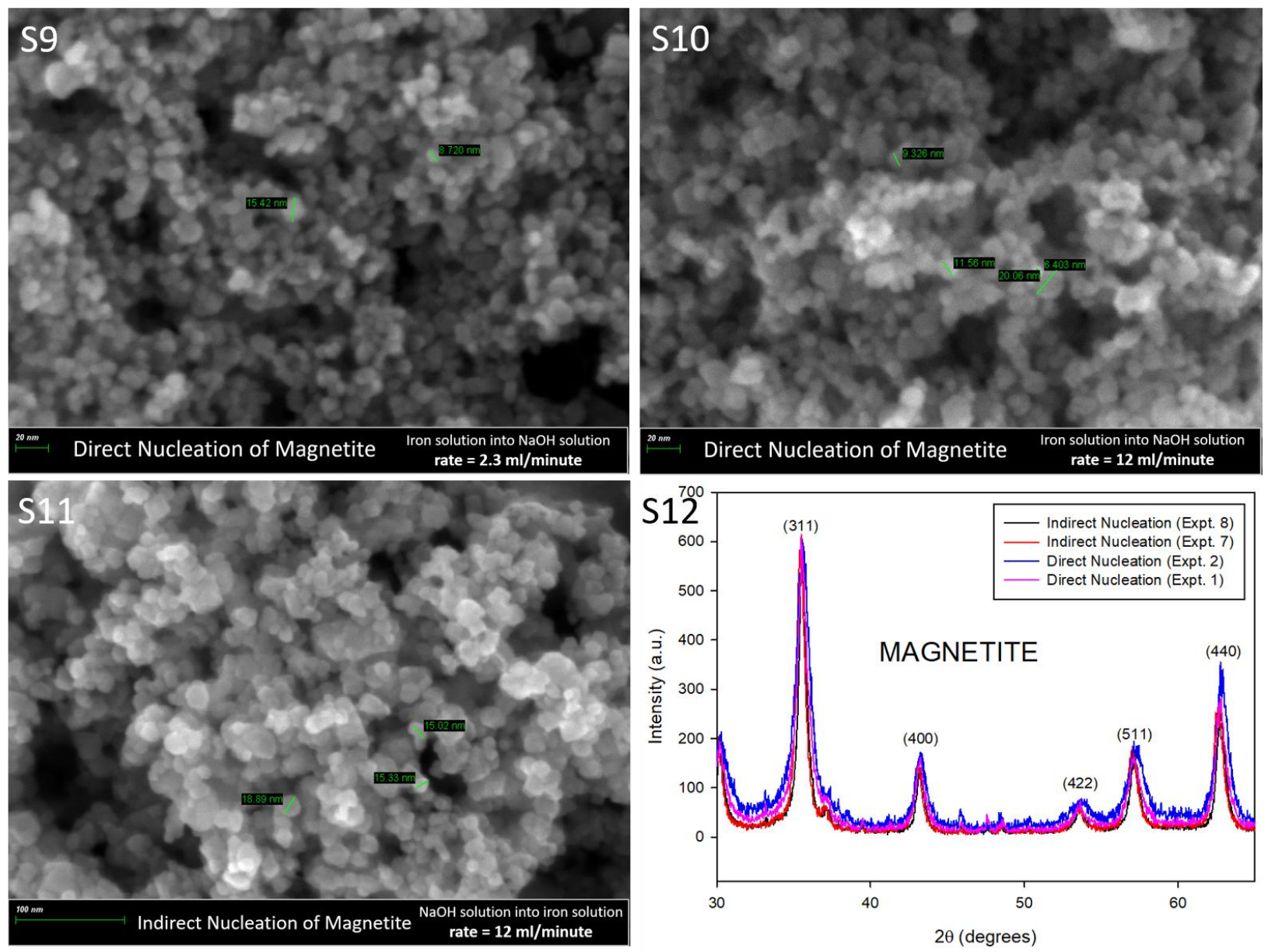

Figure 9. FESEM images at high magnification without metallic coating of magnetite recovered at the end of experiments 1 (S9), 2 (S10), 8 (S11) and X-ray diffraction (XRD) patterns for four selected powdered magnetite samples; recovered from experiments 1, 2, 7 and 8 (Table 1). 


\section{TOC Graphic}

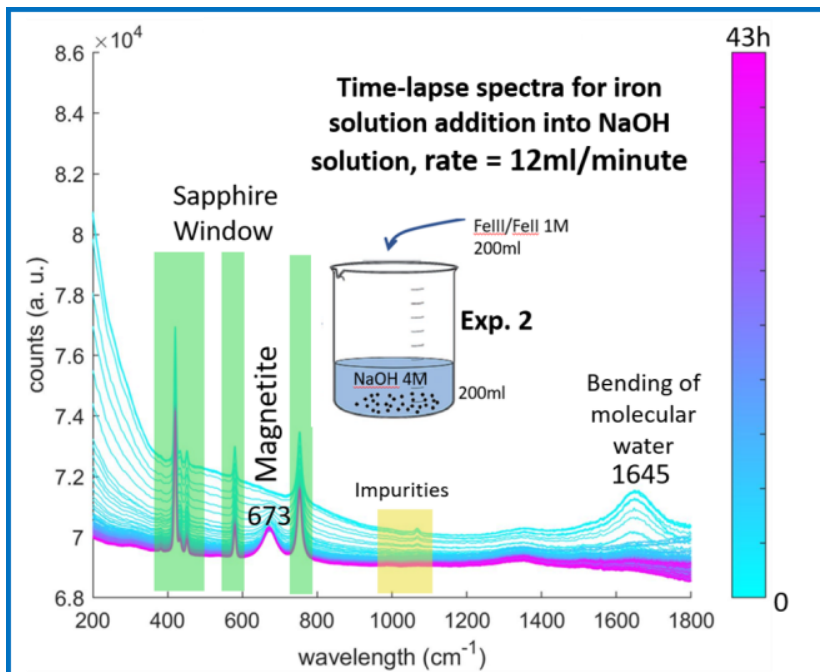

DIRECT NUCLEATION

$2\left[\mathrm{FeCl}_{2}\left(\mathrm{H}_{2} \mathrm{O}\right)_{4}\right)^{+}+[\mathrm{FeCl}]^{+}+5 \mathrm{Na}^{+}+8 \mathrm{OH}^{-} \Rightarrow$

$\mathrm{FeO} . \mathrm{Fe}_{2} \mathrm{O}_{3}+5 \mathrm{NaCl}+12 \mathrm{H}_{2} \mathrm{O}$

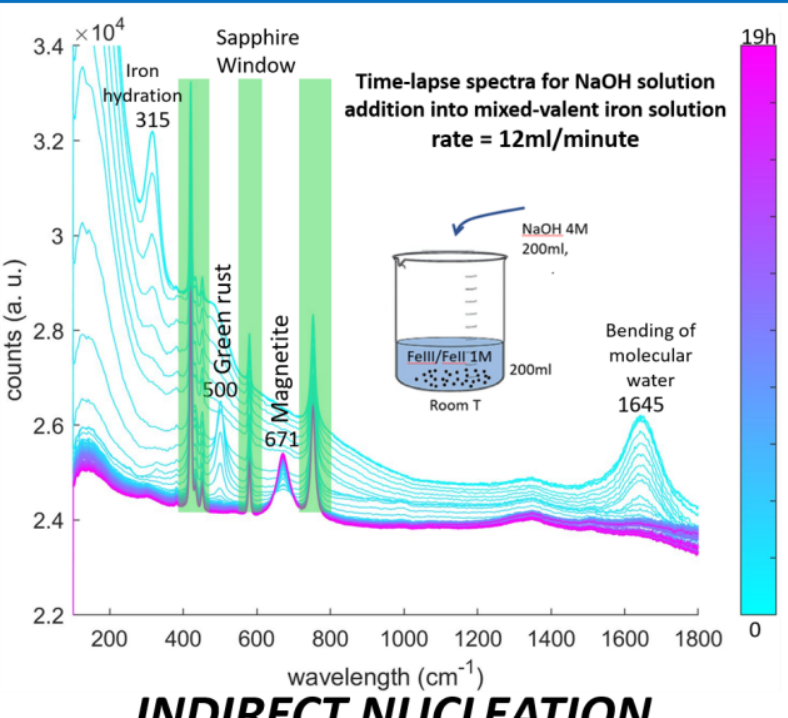

INDIRECT NUCLEATION

$\mathrm{Fe}_{3}^{I I} \mathrm{Fe}^{I I I}(\mathrm{OH})_{8} \mathrm{Cl} . \mathrm{nH}_{2} \mathrm{O}+5 \mathrm{Fe}(\mathrm{OH})_{3} \Rightarrow$

$3 \mathrm{Fe}_{3} \mathrm{O}_{4}+(11+n) \mathrm{H}_{2} \mathrm{O}+\mathrm{H}^{+}+\mathrm{Cl}^{-}$

Synopsis: The present study reports novel and complementary insights on the direct and indirect nucleation of magnetite nanoparticles monitored under in situ conditions by Raman spectroscopy in real-time. Herein, peak position, integrated peak surface area and full width at half maximum (FWHM) for iron species, transient condensate phases, magnetite and bending mode of water are fundamental parameters to identify the reaction mechanisms and quantify the kinetics of magnetite formation from ionic solutions. Moreover, the evolution of the bending mode of water during experiment probes a hydrophilic-to-hydrophobic change in suspension during magnetite formation. 